\begin{tabular}{|l|l|}
\hline & \\
\hline & $\begin{array}{l}\text { Revista Digital do Programa de Pós-Graduação em Letras da PUCRS } \\
\text { Letrônica, Porto Alegre, v. 14, n. 1, p. 1-4, jan.-mar. } 2021 \\
\text { e-ISSN: 1984-4301 }\end{array}$ \\
\hline huCRS & HUMANIDADES \\
\hline
\end{tabular}

RESENHA

\title{
O crepúsculo do contemporâneo
}

O crepúsculo do contemporâneo

\section{Matheus Rodrigues Gonçalves $^{1}$ \\ orcid.org/0000-0003-1322-9704 \\ matheus.goncalves.001@acad. pucrs.br}

Recebido em: 24/04/2020. Aprovado em: 16/12/2020 Publicado em: 9/6/2021.

\section{(c) (1)}

Artigo está licenciado sob forma de uma licença Creative Commons Atribuição 4.0 Internacional.
COSTA, Paula Cristina. O crepúsculo do contemporâneo. 1. ed. Lisboa: Nova Vega, 2020.

Em um momento no qual as pessoas do mundo todo precisam estar isoladas em suas casas para conter a ameaça de uma pandemia, e em que estudiosos da área das humanidades já especulam quais serão as consequências deste momento para os rumos da história global, um estudo literário cujo título é O crepúsculo do contemporâneo parece carregar em si certo valor premonitório. O breve estudo que traz esse significativo título, de autoria da professora e pesquisadora da Universidade Nova de Lisboa, Paula Cristina Costa, ${ }^{2}$ foi publicado no primeiro semestre do ano de 2020 pela editora Nova Vega, e faz parte da coleção Passagens, que ademais do estudo de Costa, também conta com títulos de Diderot, Deleuze, Habermas, Zambrano e outros estudiosos e estudiosas das humanidades.

Talvez o primeiro ponto da obra a ser comentado seja exatamente aquele que salta aos olhos do leitor, uma vez que o livro traz em sua capa uma reprodução de La lecture, de Renoir. A pintura apresenta a figura de duas mulheres de diferentes gerações, mas de feições e trajes similares, que se debruçam sobre um mesmo texto. Na capa, o gesto das duas mulheres parece suscitar uma possivel metáfora da contemporaneidade como uma rede de cumplicidades que ultrapassa os limites do tempo e que se encontram sobre um mesmo ponto: o texto - ideia trabalhada pela autora nas 128 páginas do estudo. Porém, poderiamos dizer também que essa reprodução funciona ainda como uma prévia da capacidade de Paula Cristina Costa em introduzir diversas roupagens ao contemporâneo advindas de elementos de outras artes, como o cinema, a dança e as artes plásticas, o que colabora para ilustrar e enriquecer os seus diálogos.

O livro está dividido em onze capítulos breves nos quais a autora reflete sobre as questões teóricas que envolvem o conceito de contemporaneidade e nos quais evoca poetas portugueses de diferentes tempos como exemplos para aquilo que ela propõe explicitar em seu estudo.

\footnotetext{
1 Pontifícia Universidade Católica do Rio Grande do Sul, Escola de Humanidades (PUCRS), Porto Alegre, RS, Brasil. Este trabalho fo realizado com o apoio do Conselho Nacional de Desenvolvimento Científico e Tecnológico (CNPq).

2 Paula Cristina Costa é professora da Faculdade de Ciências Sociais e Humanas da Universidade Nova de Lisboa. A linha de pesquisa que vem desenvolvendo aborda as noções do contemporâneo na Literatura e nas outras artes. O livro aqui resenhado está dedicado aos seus alunos.
} 
O livro abre com o prefácio intitulado "Só para Coetâneos Contemporâneos nossos", de autoria do professor da Universitat de les Illes Balears, Perfecto Cuadrado Fernández, ${ }^{3}$ no qual discorre brevemente sobre os temas a serem tratados no estudo de Costa. Em seguida, um pequeno texto como uma nota de abertura parece querer situar o leitor nas reflexões em que irá adentrar, nele a autora toma emprestadas três perguntas e respostas formuladas pelo cineasta Jean-Luc Godard em Histoire(s) du Cinema, para aplicá-las ao âmbito da literatura e do contemporâneo. ${ }^{4}$

O primeiro capitulo, intitulado "Ser ou não contemporâneo", inicia o debate baseando-se nas noções de contemporâneo e coetâneo como propostas pelo filósofo espanhol Ortega Y Gasset. Assim, Costa aplica essas noções de contemporaneidade e coetaneidade ao cotidiano do leitor, como ao dizer que nem todas as pessoas com quem cruzamos diariamente são nossas contemporâneas, mas sim coetâneas, uma vez que dividem conosco o tempo real, mas não o tempo intimo. A reflexão logo migra para o campo da história da arte, no qual aplica os conceitos já citados, de Ortega y Gasset, às obras de pintores como Goya e Bosch, a fim de compreender o local e o sentimento estético de algumas obras na história e seus diálogos com movimentos posteriores.

O segundo capítulo, intitulado "Contemporâneos e coetâneos, aprofunda-se na perspectiva de Ortega y Gasset, mas, dessa vez, agregando as noções de tempo e memória como aquelas trabalhadas por autores como Jacques Ranciére e Didi-Huberman, e ainda nas reflexões de Alain Badiou em $A$ idade dos poetas. A partir dessas reflexões, Costa assegura ao leitor de que a literatura se faz contemporânea não a partir do tempo de sua circulação, mas sim a partir de afinidades entre textos, independentemente da temporalidade. Ao final do capitulo, manifesta a intenção em analisar poemas de Cesário Verde,
Fernando Pessoa e Sophia de Mello Andresen a fim de explicitar a ideia de que a contemporaneidade diz muito mais respeito ao intimo do que simplesmente ao histórico.

O terceiro capitulo, intitulado "O contemporâneo: entre o actual e o inactual, um encontro de tempos", portanto, surge como uma forma de agregar aquilo que foi refletido até então para que o leitor possa seguir para a análise literária. Nesse capítulo, Costa traz as contribuições de Giorgio Agambem, em O que é o contemporâneo? para situar as noções de contemporaneidade e de sujeito contemporâneo a partir dos conceitos de afastamento e aproximação, nos quais o afastamento diria respeito à necessidade do sujeito contemporâneo em se afastar da ação do tempo presente para poder compreendê-lo melhor, e a aproximação à necessidade de não ignorar ou fugir integralmente desse mesmo tempo.

O quarto capitulo, intitulado "Cesário Verde: poeta simultaneamente dentro e fora do seu tempo", é aquele em que a autora tece uma espécie de cartão de visitas do poeta português Cesário Verde. O pequeno capítulo apresenta um Cesário difícil de categorizar em movimentos literários da história da literatura devido a diversos fatores. Porém, longe de ser um problema, Costa nos mostra como a inexatidão estética de Cesário faz do autor um sujeito contemporâneo por excelência, uma vez que está em diálogo constante com diferentes gerações de leitores.

O quinto capítulo, intitulado, "Análise do poema: «Contrariedades» - o encontro e o confronto entre dois tempos", como o próprio título aponta, trata-se de uma análise do poema "Contrariedades",5 de Cesário Verde, a fim de verificar o potencial de contemporaneidade da poética de Cesário. O capitulo abre com uma breve informação acerca do poema e logo segue para a análise poética, na qual a autora examina palavras e imagens a fim de situar os sentimentos do eu-lírico em um "eterno

\footnotetext{
3 O professor é catedrático de filologia galega e portuguesa na UIB, no ano de 2004 obteve o prêmio de tradução Giovanni Pontiero por sua tradução de O livro do desassossego, de Fernando Pessoa.

4 As perguntas e respostas, originalmente, "Qu'est-ce que le cinema? Rien. Que veut-il? Tout. Que peut-it? Quelque chose", logo transformam-se em "O que é a literatura? Nada. O que ela pode/consegue? Qualquer coisa" e ainda em "O que é o contemporâneo? Nada. O que é que ele deseja? Tudo. O que é que ele consegue? Qualquer coisa".

5 O texto não acompanha a reprodução dos poemas dos autores trabalhados, mas insere aqueles versos que se destacam para a proposta do estudo.
} 
presente." ${ }^{\circ}$ O subcapitulo "O encontro e o confronto entre o poeta e os outros", vem para dar o nó entre teoria e análise quando a autora destaca os pontos que fazem do poema de Cesário uma espécie de choque entre o tempo intimo do poeta angustiado e o de seus coetâneos, alheios a tudo. O subcapitulo seguinte "Cesário e Pessoa: «Contrariedades» versus «Tabacaria»", propõe a leitura comparada entre o universo dos versos de Cesário e de Pessoa. O capitulo trata também das influências de Cesário para a poética de Pessoa, traçando um breve panorama dessas influências na obra de Pessoa. Ao comparar "Contrariedades" (1876) e "Tabacaria" (1928), Costa elenca uma série de semelhanças imagéticas e sentimentais entre os dois eu-líricos.

O sexto capítulo, "Cesário e Sophia: um mesmo olhar", segue na comparação de Cesário com outros poetas de sua terra ao buscar e equiparar uma noção de olhar que permeia a poética de Cesário e Sophia. Para Costa, uma experiência do olhar é o ponto no qual estas duas poéticas se encontram e torna isso visivel ao leitor por meio do subcapítulo "Análise do poema «Noturno da Graça»", no qual, ao analisar esse poema de Sophia e suas diferentes imagens e cenários lisboetas, logo as compara àquelas mesmas imagens e cenários outrora vistos e descritos por Cesário, autenticando, assim, a ressonância de Cesário no fazer poético de Sophia através do olhar. Aqui é discutida também a presença da imagem do emparedamento nos versos de ambos os poetas, somando ainda o poeta Cesariny à discussão, e comentando o significado dessa imagem no contexto de modernidade e vida urbana.

O sétimo capitulo, "Cesário, contemporâneo?" inicia retomando a história das influências de Cesário Verde ao longo do tempo, estimulando assim uma reflexão sobre a permanência do escritor na memória daqueles autores que vieram depois. A autora, mais uma vez, insere Cesário Verde como contemporâneo, baseando-se em Agambem, e afirma que a questão da contemporaneidade está naquilo que seria um devir contemporâneo e não a simples inatividade do autor no tempo presente. Para Costa, "um texto não é, à partida, contemporâneo, ele torna-se ou não contemporâneo pela sua capacidade prospectiva que, a existir, em qualquer tempo será reactivada".7

No capítulo oito, intitulado "Mário de Sá-Carneiro, outro exemplo de uma poética fora do tempo", a autora começa por tentar localizar Mário de Sá nos rumos estéticos da modernidade da época em que produziu, reflete sobre a obra de Sá-Carneiro e seu estado de "sem tempo, numa permanente intempestividade"8 que the garante o potencial de contemporaneidade a outros leitores e autores de gerações vindouras. É comentada também a relação próxima do poeta com Fernando Pessoa e que viveram juntos "a plena criação do modernismo português",9 bem como as influências artisticas advindas das trocas de correspondências entre ambos os autores. Discute também aquilo que seria um devir contemporâneo de Sá-Carneiro a partir de suas miradas para o tempo presente, a partir dos rumos das vanguardas e das "modas parisienses", ${ }^{10}$ mas também a partir de suas miradas ao passado, como apontariam certas influências do poeta renascentista Sá de Miranda. ${ }^{11}$

O nono capitulo, "A idade dos poetas", como o próprio título sugere, trabalha com as reflexões de Alain Badiou em seu estudo homônimo para mais uma vez assegurar as diferenças entre o tempo histórico e o tempo intimo na construção do sujeito contemporâneo, mas aqui pautada especialmente na diferença entre o tempo histórico e o tempo filosófico, como pretendido por Badiou. A isso, a autora acrescenta que o contemporâneo é "um tempo intimo, de partilha de textos e autores, mais do que a data de publi-

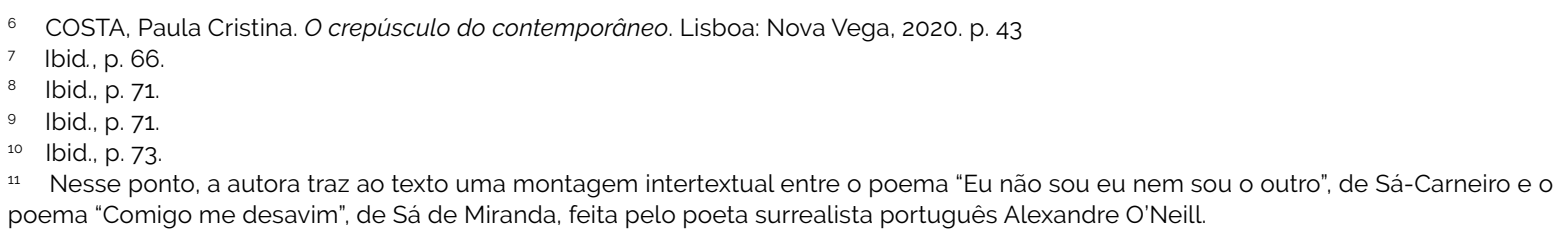


cação de um texto ou a data de nascimento de um determinado autor". ${ }^{12}$ Essa evocação teórica logo serve como ponto para debater os diálogos entre "poetas cronologicamente pertencentes à literatura portuguesa contemporânea".13

O capítulo seguinte, "Ainda o contemporâneo: Nada. Tudo. Qualquer coisa", vem para iniciar o desfecho do estudo, uma vez que nele é retomado o jogo de perguntas e respostas de Godard que foram apresentadas ao leitor ainda nas reflexões de abertura. Aqui, Costa, mais uma vez, utiliza de outras artes para tentar explicar o contemporâneo, desta vez valendo-se do filme Shall we dance (2004) para ilustrar aquilo que seria, na sua visão trabalhada até o momento, um contemporâneo que segue uma dança a dois e que, por ser a dois, é também sempre "uma chamada do outro". ${ }^{14}$

O décimo e último capítulo, que leva o nome do estudo, "O crepúsculo do contemporâneo", é uma breve e forte reflexão sobre tudo aquilo que foi discutido ao longo do trabalho. É um capítulo de miradas poéticas, no qual mais uma vez são evocadas noções advindas de outras artes para ilustrar o intento de definir o contemporâneo e o seu modus. Aqui evoca também o heterônimo pessoano Bernardo Soares para quem "o crepúsculo, a queda do dia, seria apenas o retornar da noite anterior, de muitas outras noites anteriores, como uma totalidade e não como uma separação", 15 para que mais uma vez possa ser entendida a noção de contemporâneo como dotada de um poder de ir e voltar, estar e não estar, de se aproximar e de se afastar. O livro encerra com a frase dita por Paulina, professora de dança interpretada por Jennifer Lopez no filme Shall we dance, a frase "Be this alive. Be this alive, tomorrow!" é aqui atribuida ao contemporâneo, que estaria sempre à espera de um outro para dançar o tango.

Não haveria outra forma de tratar deste estudo de Paula Cristina Costa sem trazer à reflexão o atual momento em que estamos vivendo, momento este em que a contemporaneidade parece estar parada, estática e apreensiva, e no qual é necessário que olhemos para trás, para velhos hábitos e costumes, mas sem deixar de olhar para o agora em prol do que virá em seguida. $O$ isolamento e distanciamento social que muitas pessoas enfrentam neste ano de 2020 é, em certa medida, um distanciamento social do contemporâneo, um convite para dançar o tango, para estar e não estar, para abraçar o devir da contemporaneidade nem que seja por alguns instantes.

Em um momento em que editoras, colunas culturais e sites de entretenimento listam obras literárias e cinematográficas para serem consumidas durante a quarentena, obras como El amor en los tiempos del cólera, de García Marques; Ensaio sobre a cegueira, de Saramago; e La peste, de Camus, um estudo como O crepúsculo do contemporâneo, de Costa, vem para nos munir com as reflexões e teorias necessárias para quando formos buscar reconhecer no céu do dia de hoje, os rastros do crepúsculo de ontem.

\section{Referências}

COSTA, Paula Cristina. O crepúsculo do contemporâneo. 1. ed. Lisboa: Nova Vega, 2020.

\section{Matheus Rodrigues Gonçalves}

Mestrando em Teoria da Literatura, no Programa de Pós-Graduação em Letras da Pontifícia Universidade Católica do Rio Grande do Sul (PUCRS), em Porto Alegre, RS, Brasil.

\section{Endereço para correspondência}

Matheus Rodrigues Gonçalves

Pontificia Universidade Católica do Rio Grande do Sul Av. Ipiranga, 6.681, Prédio $8,4^{\circ}$ andar, sala 403

Partenon, 90619-900

Porto Alegre, RS, Brasil 